\title{
Konstruksi Sosok Perjuangan Mgr. Albertus Soegijapranata, S.J dalam Film Soegija
}

\author{
Maria Desi Kristianingrum \\ (mariadesikristianingrum72@gmail.com) \\ (Alumni Jurusan Ilmu Komunikasi Universitas Semarang)
}

\begin{abstract}
Maria Desi Kristianingrum, 2013, the figure Struggle Construction Mgr. Albertus Soegijpranata, SJ in Film Seogija, Department of Communication Studies, Faculty of Opera-and Communication Technology, University of Semarang.

This study aims to determine the construction of the figure of the struggle Mgr. Albertus Soegjipranata, S.J in Film Soegija. The hypothesis of this study are: a) estimated a figure of media constructions struggle Mgr. Albertus Seogijapranata, SJ in the film Soegija, b) estimated the fact that minus, plus and highlighted through the storyline is presented.

Object samples taken as many as 12 scenes using data collection techniques. Researchers collected data to analyze and scrutinize the data in the form of a movie scene scene per scene. Data analysis is done by using framing your analysis. The results of this study indicate that the reality of the struggle figure Mgr. Albertus Seogijapranata, SJ in the frame by the media is to reduce and add to the actual facts, and packaged in a simple and interesting.
\end{abstract}

Kata Kunci : Film, Komunikasi massa, Kontruksi Sosial.

\section{Pendahuluan}

Dalam perkembangan media komunikasi masa sekarang ini, film menjadi salah satu media yang efektif untuk menyampaikan pesan-pesan. Film berperan sebagai sarana modern yang digunakan untuk menyebarkan hiburan yang sudah menjadi kebiasaan dan diakrabi oleh khalayak umum. Di samping itu film juga menyajikan cerita, peristiwa, musik, drama, komedi, dan sajian lainnya kepada masyarakat umum.

Suatu film pasti mengandung sebuah pesan yang ingin disampaikan sender kepada receiver melalui tanda dan simbol yang dikonstruksikan sedemikian rupa sehingga pesan tersebut membentuk suatu realitas. Didalam Analisis Framing secara sederhana dapat digambarkan sebagai analisis untuk mengetahui bagaimana realitas (peristiwa, aktor, kelompok) dibingkai oleh media
(Eriyanto, 2002:11). Pembingakian tersebut tentu saja melalui proses-proses kontruksi. Realitas sosial dimaknai dan dikonstruksi dengan makna tertentu.

Pada dasarnya framing merupakan metode untuk melihat cara bercerita sebuah film atas suatu peristiwa. Willian A. Gamson dalam Eriyanto (2007: 67), cara bercerita atau gugusan ide-ide yang terorganisani sedemikian rupa dan menghadirkan konstruksi makna peristiwa-peristiwa yang berkaitan dengan objek suatu wacana. Cara bercerita itu terbentuk dalam sebuah kemasan (package).

Dalam hal ini peneliti hanya membatasi penelitian pada Film Soegija. Film karya Garin Nugroho ini diambil dari catatan harian Mgr. Albertus Seogijapranata, S.J. Penelitian ini memiliki tujuan untuk mengetahui bagaimana sosok perjuangan Mgr. 
Albertus Soegijapranata, S.J di konstruksikan dalam film Soegija.

\section{Tinjauan Pustaka}

\section{Teori Framing Gamson dan Modiglani}

Menurut Gamson dan Modigliani, Frame adalah cara bercerita atau gugusan ide-ide yang terorganisir sedemikian rupa dan menghadirkan konstruksi makna peristiwa-peristiwa yang berkaitan dengan objek suatu wacana.Peneliti yang konsisten mengimplementasikan konsep framing, menyebut cara pandang itu sebagai kemasan (package) yang mengandung konstruksi makna atas peristiwa yang akan diberikan (Eriyanto, 2002:217-287).

\section{Konstruksi Sosial}

Dalam buku Tafsir Sosial atas kenyataan : Risalah tentang Sosiologi Pengetahuan (1990) L.Beger dan Thomas Luckmann menggambar proses sosial melalui tindakan dan interaksinya, dimana individu secara intens menciptakan suatu realitas yang dimiliki dan dialami bersama secara subjektif (Bungin, 2009:95). Mereka telah berhasil menunjukkan bagaimana posisi teoritis Weber dan Durkheim dapat digabungkan menjadi suatu teori yang komprehensif tentang tindakan sosial tanpa kehilangan logika intinya.

Pada hakikatnya isi media adalah hasil konstruksi realitas dengan bahasa sebagai perangkan dasarnya. Bahasa bukan saja sebagai alat dalam mempresentasikan realitas, namun juga bisa menentukan bentuk seperti apa yang ingin diciptakan oleh bahasa tentang realitas tersebut. Sehingga media massa mempunyai peluang besar untuk mempengaruhi makna dan gambaran yang dihasilkan dari realitas yang dikonstruksikannya.

Film
Film adalah media komunikasi seseorang atau sekelompok orang yang bermaksud menyampaikan pesan dan makan tertentu kepada para penonton atau khlayak melalui rangkaian gambar atas dasar skenario. Film dibuat berdasarkan sebuah desain yang jelas dan terarah, bahkan bisa dikatakan film adalah media komunikasi yang paling disengaja. Film merupakan bidang kajian yang sangat relevan bagi analisis struktural semiotika. Menurut Van Zoest, film dibangun dengan tandatanda semata, tanda-tanda itu termasuk berbagai sistem tanda yang bekerja sama dengan baik untuk mencapai efek yang diharapakan, rangkaian gambar dalam film menciptakan imaji dan sistem penandaan (Sobur, 2004 : 128).

\section{Metodologi Penelitian}

\section{Bentuk dan Strategi Penelitian}

Dalam penelitian ini, penulis menggunakan bentuk penelitian kualitatif interpretatif. Penelitian kualitatif merupakan penelitian yang datanya dinyatakan dalam bentuk verbal, dan analisis tanpa menggunakan teknik statistik (Sangaji E.M \& Sopiah, 2010:26)

\section{Data dan Sumber Data}

Data primer merupakan sumber data penelitian yang diperoleh secara langsung dari sumber asli (Sangadji, E.M \& Sopiah, 2010:171). Peneliti melakukan analisis terhadap simbolsimbol yang terdapat pada film Soegija.

\section{Teknik Sampling}

Peneliti memilih film Soegija sebagai objek penelitian karena Mgr. Albertus Soegijapranta, S.J adalah seseorang yang turut andil dalam memperjuangkan kemerdekaan Bangsa Indonesia dan beliau juga merupakan pahlawan bagi 
masyarakat, khususnya warga Indonesia, yaitu Mgr. Albertus

Semarang.

\section{Teknik Pengumpulan Data}

Dalam penelitian ini peneliti mengumpulkan data dengan menganalisa dan menyimak data-data yang berupa adegan film dari scene per scene, sehingga didapat 12 scene.

\section{Validitas Data}

Dalam penelitian ini yang digunakan adalah triangulasi sumber data, dengan cara studi pustaka dan juga melakukan wawancara terhadap sumber yang dipandang ahli atau mengerti sejarah Mgr. Albertus Soegijapranta, S.J. Wawancara ini digunakan untuk konfirmasi.

\section{Teknik Analisis Data}

Dalam penelitian ini peneliti menggunakan teknik framing Gamson dan Modiglani dengan cara melakuan analisis adegan scene per scene. Dari adegan tersebut dianalisis melalui unsur-unsur framing device dan reasoning device. Framing device diantaranya adalah metafora, catchpharese, exemplar dan depiction. Sedangkan reasoning device antara lain: roots, appeals to principles, dan consequenses. Setelah melakukan analisis diatas akan mendapatkan sebuah Condnsing symbol yang merupakan hasil pencermatan perangkat simbolik (framing device/perangkat framing dan reasoning device/perangkat penalaran).

\section{Hasil dan Pembahasan}

\section{Deskripsi Objek Penelitian}

Film merupakan sebuah refleksi dari peristiwa yang terjadi dalam masyarakat. Layaknya film Soegija yang menceritakan kembali sosok uskup pribumi pertama di
Soegijapranata, S.J . Melalui alur cerita yang di susun oleh Garin Nugroho, film ini berhasil mengkonstruksikan kembali sosok perjuangan Mgr. Albertus Soegijapranata, S.J dalam perjuangan kemerdekaan Indonesia. Penulis dengan menggunakan teori framing Gamson Modiglani mengambil frame-frame adegan yang mencerminkan sosok perjuangan beliau.

\section{Analisis Framing pada Film Soegija}

Garin Nugroho mengemas kembali dengan kode-kode baik verbal maupun non verbal dan juga terkandung beberapa unsur yang ditonjolkan. Adapun peristiwa yang telah dipilih dan dibingkai tersebut adalah :

1. Pendiam dan bijaksana dalam megambil keputusan.

Dalam film ini beliau dikonstruksikan sebagai orang yang pendiam, tidak banyak bicara dan bijaksana dalam mengambil keputusan yang ditunjukan dengan diam dan melihat ke arah luar jendela saat Jepang datang ke Indonesia.

2. Mempertahankan Gereja Santo Yusuf Gedangan

Mempertahankan Gereja Santo Yusuf yang hendak di pakai markas oleh Tentara Jepang, namun dengan tegas Mgr. Albertus Soegijapranata, S.J menjawab “ Ini tempat yang disucikan, penggal dulu kepala saya, baru tuan boleh memakainya."

3. Mengirimkan surat kepada Sultan Syahrir

Saat kota Semarang mengalami kekacauan saat masa penjajahan Belanda, beliau mengirimkan surat kepada Sultan Syahrir agar dengan segera Semarang di beri seorang pemimpin dan juga meminta bantuan untuk bahan-bahan makanan.

\section{Konfrensi Pres}

Saat terjadi pertempuran lima hari di Semarang, Mgr. Albertus Soegijapranata, S.J memanfaatkan kunjungan komandan 
tentara Inggris ke Gereja Santo Yusup Gedangan untuk berdiplomasi dengan komandan tentara Jepang agar Jepang segera mengehentikan peperangan tersebut.

5. Memindahlan keuskupan Semarang ke Yogyakarta

Ibu kota Indonesia pada saat itu berpindah ke Yogyakarta, dan untuk mendukung gerakan kemerdekaan serta untuk mempermudah komunikasi dengan para pemimpin negara, beliau memutuskan turut berpindah dari Semarang ke Yogyakarta.

6. Melakukan Diplomasi dengan Negara Vatikan

Belanda dengan membonceng tentara Nica kembali lagi untuk menjajah Indonesia. Saat itu wilayah Indonesia sudah diblokade, namun pada akhirnya Mgr. Albertus Soegijapranata, S.J dapat menembus blokade dan melakukan diplomasi dengan negara Vatikan. Beliau membawa hasil yang mengagetkan negara Belanda, karena wakil dari negara Vatikan yaitu Mgr. D'Ardoye datang ke Gedung Agung Yogyakarta untuk mengakui kemerdekaan Indonesia seacara resmi.

7. Mengambil keputusan yang bijaksana

Salah satu keputusan Mgr. Albertus Soegijapranata, S.J yang bijaksana dapat dilihat dari adegan dimana beliau mengijinkan para warga untuk mengungsi di Gereja Bintaran. Selain itu juga beliau memberi instruksi kepada pelayan agar lebih mendahulukan pengungsi daripada melayaninya. Memintakan bantuan bahan makanan dan obat-obatkan kepada jemaat dan negara lain untuk mencukupi kebutuhan para pengungsi. Beliau juga mengunjungi para pengungsi yang sedang sakit. Kedua hal inilah yang dikonstruksikan kembali dalam film Soegija dengan tujuan ingin memperlihatkan kepedulian Mgr. Albertus Soegipranata, S.J kepada rakyat dan negara.

\section{Pembahasan}

Analisis framing merupakan salah satu alternatif model analisis yang dapat mengungkap rahasia dibalik sebuah perbedaaan bahkan pertentangan media dalam mengungkapkan fakta. Analisis framing dipakai untuk mengetahui bagaimana realitas dibingkai oleh media. Dengan demikian realitas sosial dipahami, dimaknai, dan dikonstruksi dengan bentukan dan makna tertentu.

Uskup pribumi pertama di Indonesia ini dalam film Soegija dikonstruksikan sebagai seseorang yang pendiam dan bijaksana. Dalam film ini Mgr. Albertus Soegijapranata, S.J tidak banyak bicara dan dengan wajah yang selalu serius. Walaupun seorang yang pendiam, namun beliau banyak mengambil tindakan-tindakan yang bijaksana untuk memperjuangkan kemerdekaan Indonesia. Seperti yang dikonstruksikan dalam alur cerita Film Soegija ini. Perjuangan beliau pertama digambarkan dengan adegan mempertahankan Gereja Santo Yusup Gedangan. Fakta yang sebenarnya mempunyai cerita yang panjang dalam percakapan antara komandan tentara Jepang dan Mgr. Albertus Soegijapranata, S.J. Namun dalam film ini fakta tersebut dibingkai sehingga ada sebagian peristiwa yang ditonjolkan, yaitu sanggahan beliau " Ini tempat yang disucikan, penggal dulu kepala saya, baru tuan boleh memakainya. "

Dua tahun setelah beliau menjabat sebagai uskup di Semarang, tentara Jepang datang untuk menjajah Indonesia. Saat itu juga terjadi pertempuran antara warga Seramarang dan Jepang selama lima hari. Pertempuran tersebut membuat keadaan Semarang menjadi kacau, 
kelaparan, penjarahan dan kejahatan menyebar luas. Oleh karena itu Mgr. Albertus Soegijapranata, S.J mengirimkan surat kepada Sultan Syahrir agar segera dikirimkan pemimpin untuk kota Semarang serta meminta bantuan bahan makanan untuk mengnanggulangi kelaparan yang ada. Selain itu, untuk menghentikan pertempuran yang memakan banyak korban ini beliau mengadakan pertemuan dengan komadan tentara Jepang dan Inggris untuk mendesak Jepang agar cepat menghentikan pertempuran ini. Peristiwa tersebut hanya dikosntruksikan dengam adegan konfrensi pres, dimana beliau di dampingi dengan komandan Jepang dan Inggris.

Setelah Semarang aman dengan berhentinya pertempuran lima hari tersebut. Beliau memutuskan berpindah ke Yogyakarta yang saat itu menjadi ibu kota Indonesia untuk membantu mendukung pemerintahan. Selama berada disana beliau berhasil menembus blokade Belanda dan melakukan diplomasi dengan negara Vatikan. Hasil dari diplomasi ini dikemas secara berbeda, dalam Film Seogija digambarkan dengan pernyataan Pak Besut saat melakukan siaran yang melaporkan bahwa Mgr. D'Ardoye wakil dari negara Vatikan datang ke gedung agung untuk menngakui secara resmi kemerdekaan Indonesia.

Gerakan perjuangan lainnya dibingkai pada saat Mgr. Albertus Soegijapranata, S.J masih berada di Yogyakarta. Beliau mengijinkan Gereja Bintaran agar dapat digunakan untuk tempat pengungsian melalui percakapannya dengan Lantip, "Yen ora ono panggon, lebokke Grejo Bintaran wae" yang artinya "Jika tidak ada tempat, masukan mereka ke Gereja Bintaran." Bukan hanya sampai disitu, beliau juga memikirkan keadaan para pengungsi. Adegan yang membuktikan bahwa beliau juga memikirkan nasib para pengungsi adalah dimana beliau perbincangbincang kepada petugas PMI bahwa beliau akan memintakan bantuan makanan dan obat-obatan kepada jemaat dan dunia luar. Selain itu beliau juga memberikan instruksi kepada petugas PMI untuk lebih mengutamakan melayani pengungsi dari pada melayaninya. Perhatiannya terhadap para pengungsi juga ditunjukan ketika adegan beliau mengunjungi pengungsi yang sedang sakit dengan merunduk dan memegang dahinya.

\section{Kesimpulan}

Berdasarkan hasil analisis data, maka penulis menarik kesimpulan bahwa media khususnya film sebagai sarana komunikasi media massa tidak dapat dikatakan netral. Karena melihat sajian film Seogija yang diambil dari catatan harian Mgr. Albertus Seogijapranata, S.J memiliki sedikit banyak perbedaan antara data sejarah dan fakta yang ditampilkan dalam film tersebut. Film ini mencoba mengkonstruksikan kembali sosok perjuangan Mgr. Albertus Soegijapranata, S.J melalui adeganadegan tertentu yang sudah dikemas secara sederhana dan menarik.

\section{Daftar Pustaka}

Alex Sobur. 2001. Analisis Teks Media, Suatu Pengantar Untuk Analisis Wacana, Analisis Semiotik, dan Analisis Framing. Remaja Rosdakarya. Bandung.

Anhar Gonggong. 2012. Mgr. Albertus Soegijapranata SJ Antara Gereja dan Negara. Jakarta Grasindo. 
Deddy Mulyana. 2005. Komunikasi Efektif Suatu Pendekatan Lintas Budaya. Bandung : PT Remaja Rosdakarya Bandung.

Denis McQuail. 1987. Teori Komunikasi Massa. Jakarta : Erlangga.

Djam'an Satori \& Aan Komiariah. 2011. Metode Penelitian Kualitiatif. Bandung : Alfabeta.

Eriyanto. 2002. Analisis Framing, Konstruksi, Ideologi, dan Politik Media. LkiS Yogyakarta. Yogyakarta.

G. Budi Subanar. 2012. Kilasan Kisah Soegijapranata. Yogyakarta : Penerbit USD.

G. Budi Subanar. 2003. Soegija Si Anak Betlehem van Java. Yogyakarta :Penerbit Kanisius.
Pawito. 2007. Penelitian Komunikasi Kuaitatif. Yogyakarta : LkiS Yogyakarta.

Roland Barthes. 2004. Mitologi. Yogyakarta : Kreasi Wacana.

Sangadji. E.M \& Sopiah. 2010. Metodologi Penelitian. Yogyakarta : Andi Offset.

(http://herusutadi.blogdetik.com/200 9/10/12/sejarah-perkembangan-filmindonesia, Di akses, 11 September 2012, 22:05)

(http://entertainment.kompas.com/re ad/2011/11/04/20034497/.Soegija.Fi 1m.Termahal.Garin.Nugroho, Di akses, 11 September 2012, 22:11) (http://www.hidupkatolik.com/ Di akses, 20 November 2012, 12:09) 